\title{
Tentative study of flow patterns in the North Aegean Sea using NOAA-AVHRR images and 2D model simulation
}

\author{
G. Zodiatis ${ }^{1}$, S. Alexandri ${ }^{2}$, P. Pavlakis ${ }^{2}$, L. Jonsson ${ }^{3}$, G. Kallos ${ }^{4}$, A. Demetropoulos ${ }^{1}$, G. Georgiou ${ }^{5}$, \\ A. Theodorou $^{6}$, E. Balopoulos ${ }^{2}$ \\ ${ }^{1}$ Laboratory Physical Oceanography, Department Fisheries, Aeolou 13, 1416 Nicosia, Cyprus \\ 2 National Centre for Marine Research, Hellenikon, 16604 Athens, Greece \\ ${ }^{3}$ University of Lund, PO Box 118, S-22100 Lund, Sweden \\ ${ }^{4}$ University of Athens, Department of Applied Physics, Ippocratous 33, Athens, Greece \\ ${ }^{5}$ University of Cyprus, Department of Mathematics and Statistics, Nicosia, Cyprus \\ ${ }^{6}$ University of Thessaly, Laboratory Oceanography, Pedio Areos, 38334 Volos, Greece
}

Received: 16 September 1994/Revised: 19 April 1996/Accepted: 20 May 1996

\begin{abstract}
A statistical technique for image processing, the maximum cross correlation (MCC) method, was utilized on sequences of NOAA-AVHRR thermal data in order to explore the surface advective current dynamics at the discharge region of the Hellespont in the North Aegean Sea. A 2D numerical flow model was also used in order to simulate the barotropic flow pattern of the surface water layer. The model was forced with diurnal wind fields obtained for the same period as the satellite infrared images. The currents (magnitude and direction) derived from the two methods compare satisfactorily despite the fact that some model simplifications were made.
\end{abstract}

\section{Introduction}

A considerable amount of in situ data is needed in order to study mesoscale sea surface phenomena linked to flows through straits, eddies, jet currents, upwelling etc. The collection of standard physical oceanographic information in the field is costly, time consuming and cannot constitute a simultaneous representation of the observations in the open sea areas. This is, of course, especially evident in cases of practical interest where quick decisions are required, as for instance in the case of contaminant transport and dispersion.

The use of satellite infrared data in oceanographic studies has a unique potential in providing mesoscale and synoptic sea surface temperature information concerning flow patterns. One way of obtaining quantitative information (magnitude and direction) on mesoscale surface water movements is to apply image processing techniques to sequential, remotely sensed (satellite) thermal images. The most common method is the maximum cross-correlation

Correspondence to: $\mathrm{G}$. Zodiatis method (MCC) (Emery et al., 1986; Garcia, 1992). This method is based on tracing, by means of statistical methods, the horizontal displacement of surface water temperature patterns during the time period between two satellite images (interval one or two days). The more well defined the temperature gradients patterns are the easier will the tracing be (Jonsson, 1989; Fedorov and Ginsburg, 1992).

In this work, we apply and evaluate the MCC method on NOAA-AVHRR thermal data in order to determine the advective movements of the surface water in the discharge region of the Hellespont into the NE Aegean Sea (Fig. 1). Numerical experiments were made to simulate the 2D model flow patterns forced with observed meteorological conditions.

\subsection{Hydrography review}

The surface water of Black Sea origin (BSW) enters into the North Aegean through the strait of the Hellespont (Fig. 2) throughout the year (Ovchinnikov et al., 1976; Zodiatis, 1994). The BSW with low salinity (29-34) and low temperature (during summer $18-23^{\circ} \mathrm{C}$ ) is advected into most of the Northern Aegean Sea. The interaction between water masses with different characteristics and origin, results in the formation of a well-defined haline frontal zone between the less saline BSW and the saline (39-39.1) water of Levantine origin (Ivanov et al., 1989; Zodiatis and Balopoulos, 1993). The latter saline water intrudes into the SE area of the North Aegean from the Cretan Sea.

Below the BSW layer (20-40 m deep in the Northern and NW Aegean) a well-developed vertical halocline with highly stable buoyancy conditions is established, due to the low salinity of the surface water layer, despite the intense cooling and evaporation during winter and summer seasons (Zodiatis, 1994). This was verified through the realization of various 1D mixed layer numerical simulations of the autumnal winter convective mixing processes (Gertman and Popov, 1989; Zodiatis, 1994). 


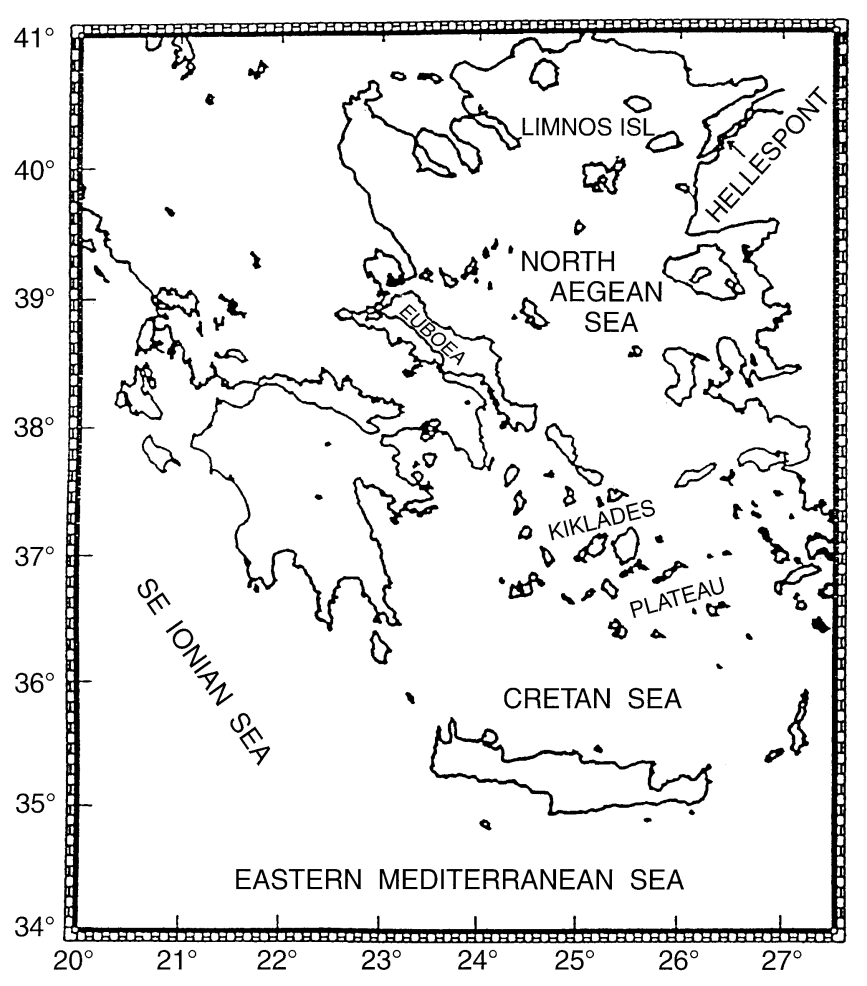

Fig. 1. Morphology of the Aegean Sea

In the Aegean Sea upwellings occur along the eastern physiographic borders of the sea (Metaxas, 1973), due to the summer (August-September) strong northerly winds (etesian winds). Subsurface cool water upwells and creates surface temperature differences $\left(3-5^{\circ} \mathrm{C}\right)$ establishing a thermal front between the eastern and western regions of the North Aegean Sea (Zodiatis and Balopoulos, 1993).

The land-water distribution of the area, the wind field and the fluxes through the Hellespont Strait (vary between 300 and $700 \mathrm{~km}^{3} /$ year) (Latif et al., 1992) favour the advection of the BSW in the North Aegean Sea towards the passages of the Kiklades Plateau. Modified BSW was also been traced as far south as in the area of the western Cretan Arc straits, between the SE Ionian and western Cretan seas (Zodiatis, 1993). The main feature of the circulation in the North Aegean Sea is the BSW current, with maximum surface velocities between 20 and $45 \mathrm{~cm} \mathrm{~s}^{-1}$ (Fig. 2b). In general, the modified BSW is directed from the strait to the SW, south of Limnos island in summer, and north of it in winter. Moreover, small-scale cyclonic and anticyclonic flow regions are formed along the main direction of such movement. Usually, cyclonic flow regions are found to the south or east of the main current trajectory, while anticyclonic flow regions are found to the north or west, between the current and the mainland of Greece (Zodiatis, 1994).

In the North Aegean Sea there are significant temporal and spatial variations of the wind field. This is due to the existing physiographic characteristics of the region (i.e. topography and land-water distribution). The area of the Hellespont Strait is considered to be the physical exit of the air masses from the Black Sea to the Aegean (Kallos et al., 1993). These air masses are channelled across the Aegean Sea, between Greece and the Asia Minor. During summer, northeastern sector winds are observed due to the fact that over the Hellespont there is a pressure gradient formed between the high-pressure system dominating the Mediterranean and Black Sea and the thermal lowpressures system over Asia Minor. This meteorological phenomenon and northerly winds is known as etesian winds.

To our knowledge, this work is the first attempt to use satellite data and the MCC method in order to investigate the variability of the advective currents at a synoptic scale in the discharge region of the Hellespont. However, the analysis of long-term satellite infrared NOAA-AVHRR images (obtained between 1980 and 1987) by Le Vourch et al. (1992) provides significant information on the monthly sea surface temperature characteristics, thermal fronts and the advective flows in the entire Mediterranean Basin as well as in the Northern Aegean Sea.

The following parts of this study will be devoted to the description of: (a) the MCC method used to determine the advective currents by processing sequential NOAAAVHRR thermal data, and (b) the 2D model used to simulate the wind-driven flow pattern of the North Aegean Sea. Finally, results and conclusions will be presented.

\section{The maximum cross-correlation method}

The MCC method is used to analyse satellite data in order to obtain qualitative and quantitative information on surface flow patterns. This method is based on a statistical analysis of the sea surface temperature patterns in a sequence of NOAA-AVHRR scenes in order to derive horizontal advective surface water movements. This is done by the determination of the displacement of a temperature pattern within a selected window size (Jonsson, 1993) during the time between two satellite images. The window grid $(K x, K y)$ used for the present estimation of current vectors consists of $14 \times 14$ pixels with a pixel size of about $1 \mathrm{~km}$ (Fig. 3). The size of the window is an empirically based compromise between the good quality resolution of the flow and the risk of obtaining erroneous correlation displacements.

The displacement is calculated by maximising the cross-correlation between the patterns in the two sequential images. Knowledge of the displacement and the time period suffices for the determination of an average advectional velocity.

For such an approach a window size with $K x, K y$ pixels is assigned in the sea area of interest in the first NOAA-AVHRR scene (Fig. 3). A window of the same size is moved within the second image around a search area, large enough to contain the displaced pattern within the window in the first image. The search area is centred around the corresponding location of the window in the first image. The windows are typically of a square shape and with sizes of the order of $10 \times 10$ up to $20 \times 20$ pixels (Jonsson, 1993). According to previous experiments on the 

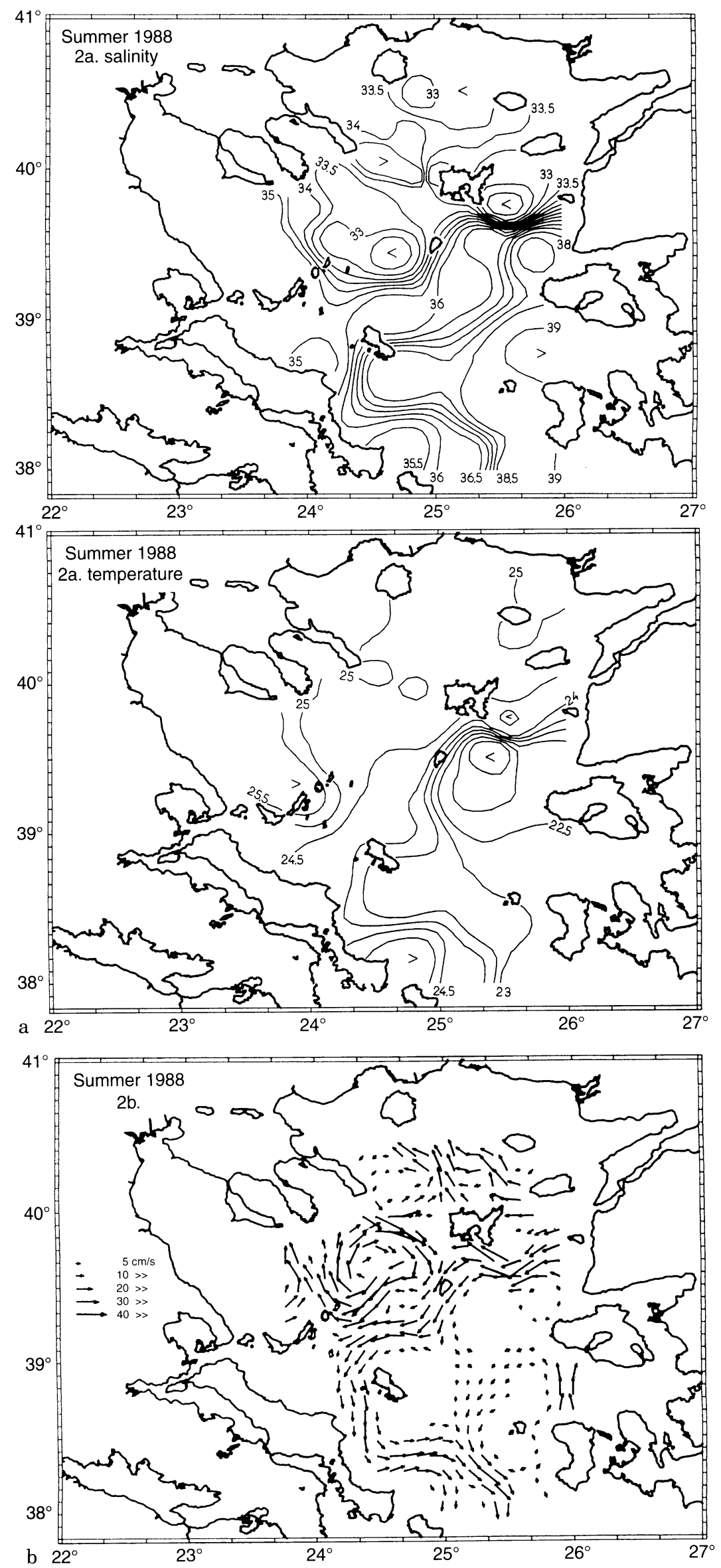

Fig. 2. a Horizontal distribution of surface salinity, used as tracer for the BSW in the Aegean Sea, indicating the patch of the BSW in the discharge region of the Hellespont, summer period (after Zodiatis and Balopoulos, 1993). b Surface geostrophic currents in the North Aegean, summer period, revealing the BSW flow, the anticyclonic eddy in the NW Aegean and the weak northward flow in the SE part of the sea (after Zodiatis, 1994) 


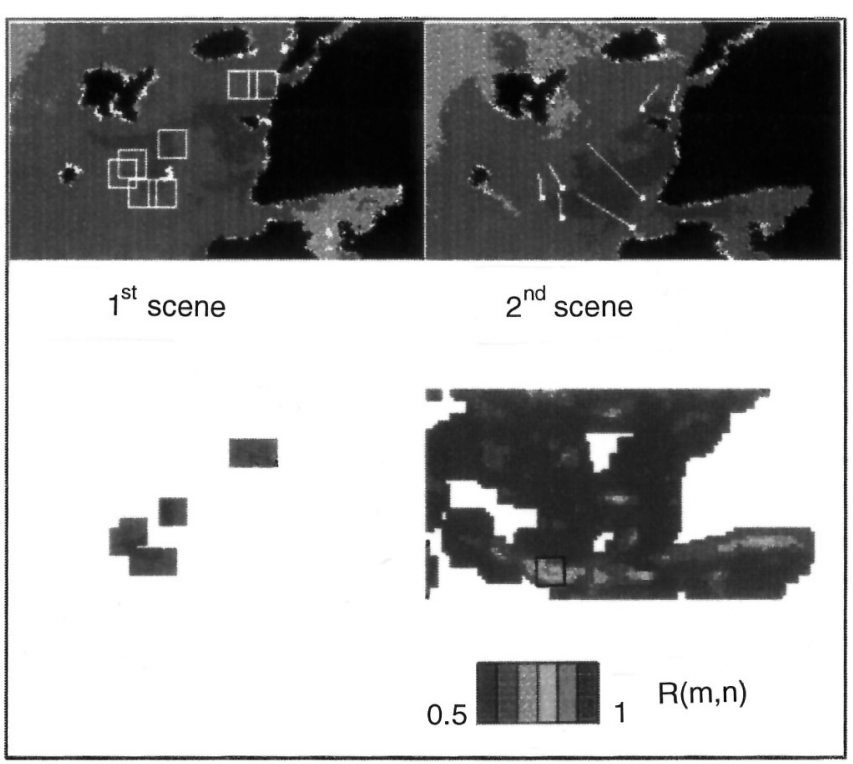

Fig. 3. Visual example of MCC method. Several windows are fixed in the first scene, while in the 2nd one the windows move within a search area. Pattern of the correlation $(R(m, n))$ in the search area of the 2 nd scene correlated with the window of the first scene. The maximum $R(m, n)$ displacement between two sequential images is used for advectional current vectors estimation

window size (Jonsson, 1993), there is a lower limit for the window size. When it is very small, erroneous displacements are produced, due to the effect of random variations of the digital levels of the pixels. The upper limit (about $20 \times 20$ pixels) is a consequence of two conflicting aspects, increasing the window size reduces the influence of random temperature values variations in different pixels, whereas decreasing the window size enhances the details of the advective velocity fields.

For each location of the window in the second scene the cross-correlation between the pixel values of the two sequential scenes is estimated. The location of the window in the second scene with the best possible cross-correlation is assumed to define the displacement of the temperature pattern due to advection (Fig. 3). For the present application of the MCC method, windows with maximum cross-correlation coefficients less than 0.65 were not used for velocity determination. The value 0.65 is rather high according to earlier applications, thus minimising the risk for erroneous displacements.

Finally, on the basis of the pixel size, the displacement obtained in pixel units for maximum cross-correlation and the time interval between the two successive scenes, the surface current (magnitude and direction) can be derived (Fig. 3). The same procedure is repeated for a new selected location of the window in the first image. Thus, information on mesoscale surface advective currents in an area such as the Hellespont Strait region can be obtained with this procedure.

The use of SST gradients (edge enhancement) will make the statistical pattern recognition (MCC method) much more difficult, while the use of 10-bit $\mathrm{CH} 4$ and $\mathrm{CH} 5$ data via temperature determination will increase the amount of noise in the pixels. The MCC method is basically a pattern recognition method not necessarily based on absolute temperatures. As indicated by Jonsson (1993) the MCC method normally works best if NOAA-AVHRR data from only one of the thermal channels is used, i.e. either $\mathrm{CH} 4$ data or CH5 data and with the use of the full resolution potential (10-bit data). For this study, 8-bit data from one thermal channel (CH4) were used.

The degree of interrelation between two windows ( $f$ in the first scene and $g$ within the search area $S$ in the second scene) is commonly defined by the following correlation coefficient (Moik, 1980):

$R(m, n)=\frac{\sum_{j} \sum_{k} f(j, k) * g(j+m, k+n)}{\left[\sum_{j} \sum_{k} f(j, k) 2 * \sum_{j} \sum_{k} g(j+m, k+n) 2\right]^{1 / 2}}$

For matching purposes it is assumed that $m, n$ is the $2 \mathrm{D}$ position of a search area $S$ in the second image $g$ relative to a template in the first image $f$. The maximum $R(m, n)$ value displays the best correlation between the $f$ and $g$ windows, which have to be of the same size. It should be added that this application of the MCC method does not involve any rotation of the windows on the $\mathrm{X}, \mathrm{Y}$ axis. Significant rotation of the search area will decrease the correlations.

\section{2D model flow simulation}

A numerical 2D flow model using vertically integrated finite differences on the basis of the shallow water equations of momentum and continuity has been developed in order to simulate the synoptic-scale flow pattern of the North Aegean Sea. The model takes into account the realistic wind fields, mean average flows through the strait and the boundary conditions of the geomorphology of the North Aegean Sea. The database for this numerical experiment comprised the following: (a) the daily average values of the wind velocity fields, collected from 26 June to 5 July 1993 in several meteorological stations around the Aegean Sea (Hellenic Meteorological Service), (b) bathymetric data, in the case of the application of the two layer 2D flow model, and (c) historical and recent in situ flow velocity measurements at the Hellespont Strait (Ovchinnikov et al., 1987; Latif et al., 1992). The wind stress driven components were computed from empirical relations on the basis of the wind velocities (Lee et al., 1984). The chosen grid size is $10 \mathrm{~km}$, which gives sufficient mesoscale spatial resolution for the simulated flow pattern of the North Aegean Sea.

The governing equations in the 2D model are (Ramming and Kowalik, 1980):

(a) the momentum equations

$$
\begin{aligned}
& \partial U / \partial t+U \partial U / \partial x+V \partial U / \partial y-f V \\
& \quad=-g \partial \zeta / \partial x+\tau s x / h \rho-\tau b x / h \rho+A h \Delta U \\
& \partial V / \partial t+U \partial V / \partial x+V \partial V / \partial y+f U \\
& \quad=-g \partial \zeta / \partial y+\tau s y / h \rho-\tau b y / h \rho+A h \Delta V
\end{aligned}
$$


(b) the continuity equation

$\partial \zeta / \partial t+\partial(h U) / \partial x+\partial(h V) / \partial y=0$

with the following boundary conditions

$\partial U / \partial n=0 ; \quad \partial V / \partial n=0$

Here $U$ and $V$ are the depth averaged velocities in the $x$ and $y$ directions, $\zeta$ is the sea level, $\rho$ is the mean sea water density, $h$ denotes the total water depth of the upper layer, $\tau s x, \tau s y$ are the $x$ and $y$ components of the wind stress, $\tau b x$, $\tau b y$ are the $x$ and $y$ components of the bottom stress, $A h$ is the coefficient of horizontal eddy viscosity, $\Delta$ is the $2 \mathrm{D}$ Laplacian operator, $f$ is the Coriolis parameter and $g$ is the gravity acceleration.

The relevant model parameters are the following:

$f=2 * \omega * \sin (\varphi)=8.9 \mathrm{e}-5,-=38^{\circ}$ central latitude

$A h=500 \mathrm{~m}^{2} / \mathrm{s}$

$g=9.8 \mathrm{~m} / \mathrm{s}^{2}$

$\tau s=\rho \alpha * W x, y *(W x, y)$ wind stress forcing

$\tau b=k * U x, y *(U x, y)$ bottom friction

$k=0.0025$ bottom drag coefficient

$\Delta x, \Delta y=10 \mathrm{~km} \times 10 \mathrm{~km}$ horizontal grid interval

$\Delta t=75 \mathrm{~s}$ time step

$\rho=1025 \mathrm{~kg} / \mathrm{m}^{3}$, mean water density

The knowledge of the horizontal components of the velocity derived from the $2 \mathrm{D}$ flow model is considered sufficient for the reconstruction of the barotropic flow response, especially when no in situ density information is available (Ramming and Kowalik, 1980). The applicability of such a model is based on the hydrography of the North Aegean Sea characterised in most part by a rather homogeneous upper layer $(20-40 \mathrm{~m})$ of modified BSW origin with high vertical stability buoyancy condition. Earlier applications of this model (Fig. 4) have also demonstrated its ability to describe a number of observed mesoscale flow characteristics of the Aegean Sea (Krestenitis et al., 1987; Zodiatis et al., 1994; Valioulis and Krestenitis, 1994). The simulation of the wind-driven currents, in the case of northerly winds and strong inflow from the Hellespont Strait, generates a flow pattern with characteristics close to the general circulation (Fig. 2b), i.e. the model is capable of simulating the BSW current flowing SW and the weak northward flow in the SE part of the sea. Similar calculations for the Baltic Sea (Kielmann, 1982) were used for comparison to advective currents estimated on the base of the MCC method (Jonsson, 1993).

The present flow model simulations concerned a period of 8 days and zero initial conditions for $U, V, \zeta$. First, the model was forced with an average flow $(8-12 \mathrm{~cm} / \mathrm{s})$ through the Hellespont strait and with daily wind fields corresponding to the same periods as the NOAA-AVHRR scenes. In a second numerical experiment the bathymetry of the area was also used. In this case the equations of momentum and continuity (2-3) were modified for a twolayer 2D model (Sekine, 1990) in order to simulate the flow pattern of the upper layer taking into account the layer below ( $40 \mathrm{~m}$-bottom) and the modification of the circulation due to bathymetry.

\section{Results and discussion}

\subsection{NOAA-AVHRR thermal sea surface images}

Four sequential NOAA-11 AVHRR 8-bit data sets from one thermal infrared channel $(\mathrm{CH} 4)$ with actual thermal

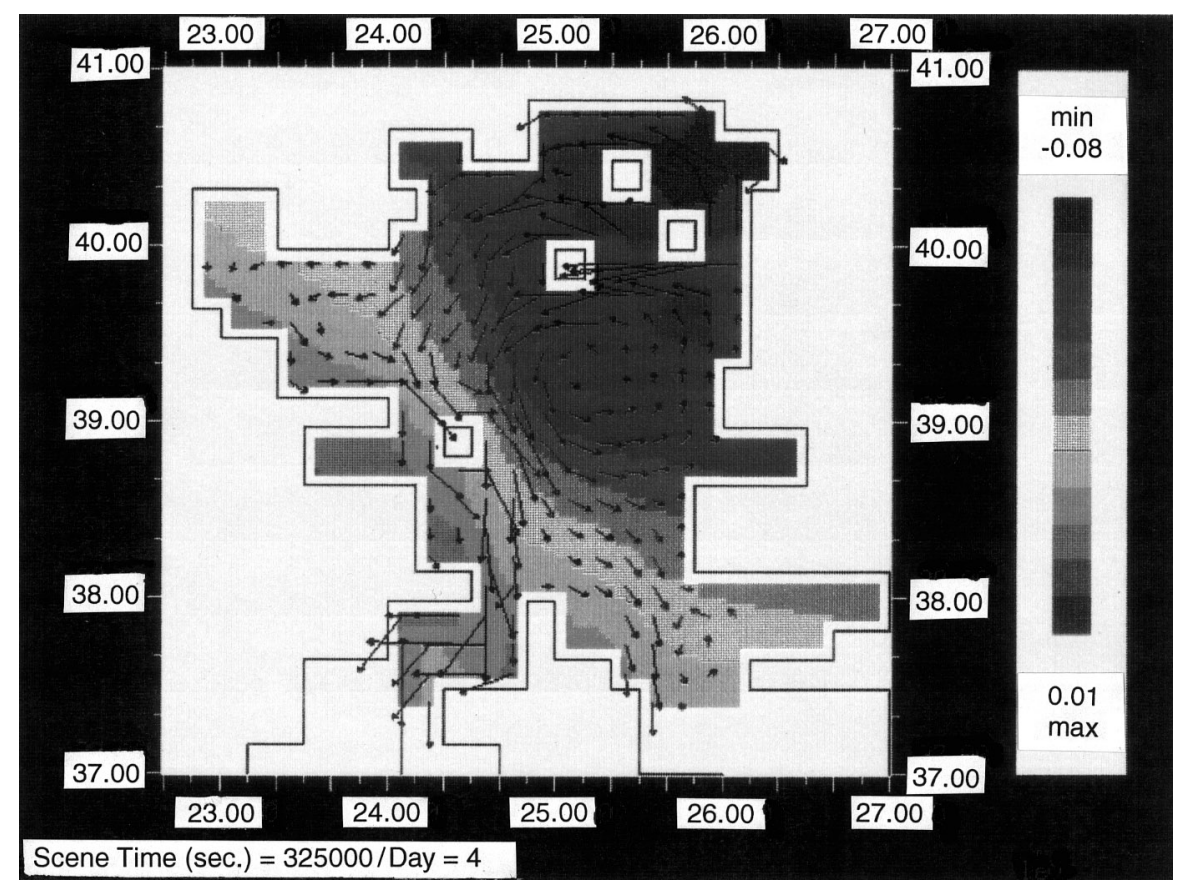

Fig. 4. A study case of barotropic flow in the North Aegean, with strong northerly winds and discharge from the Hellespont, where the flow model used is capable of simulating the main features of the local circulation 


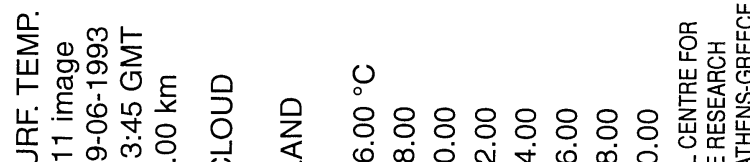

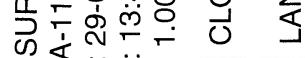

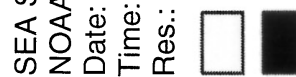

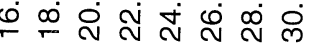

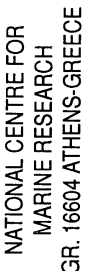

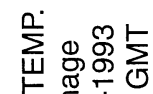

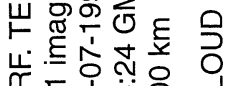

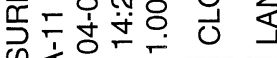

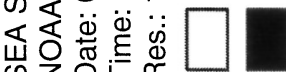
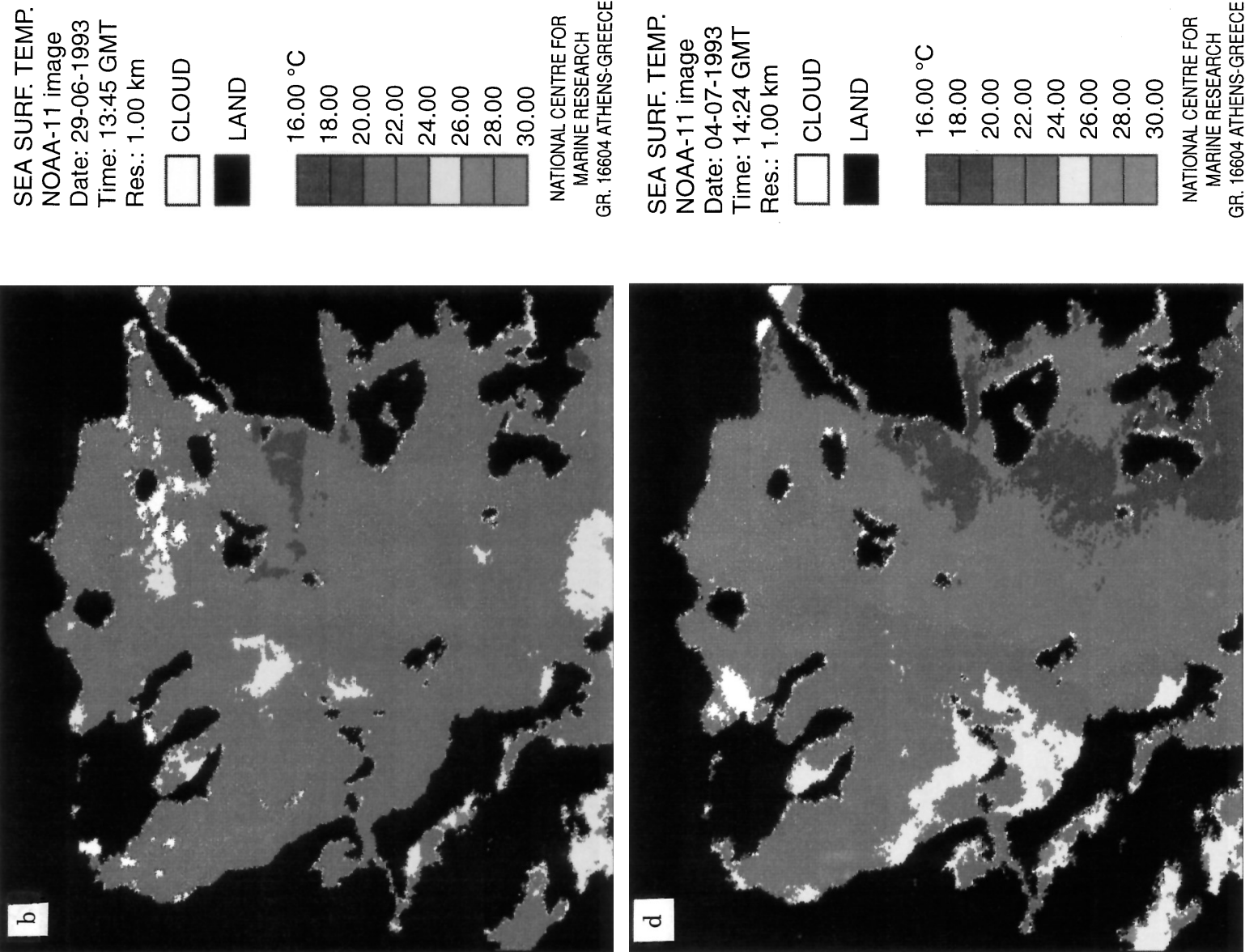

突怠

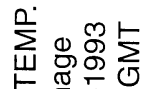

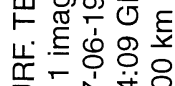
क

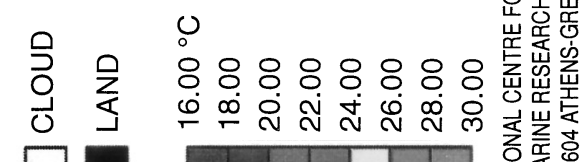

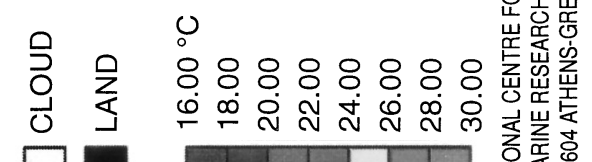

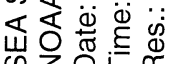

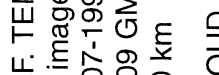

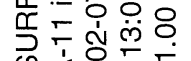

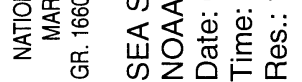

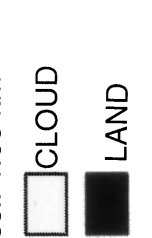

\section{0}

동 凹之吅
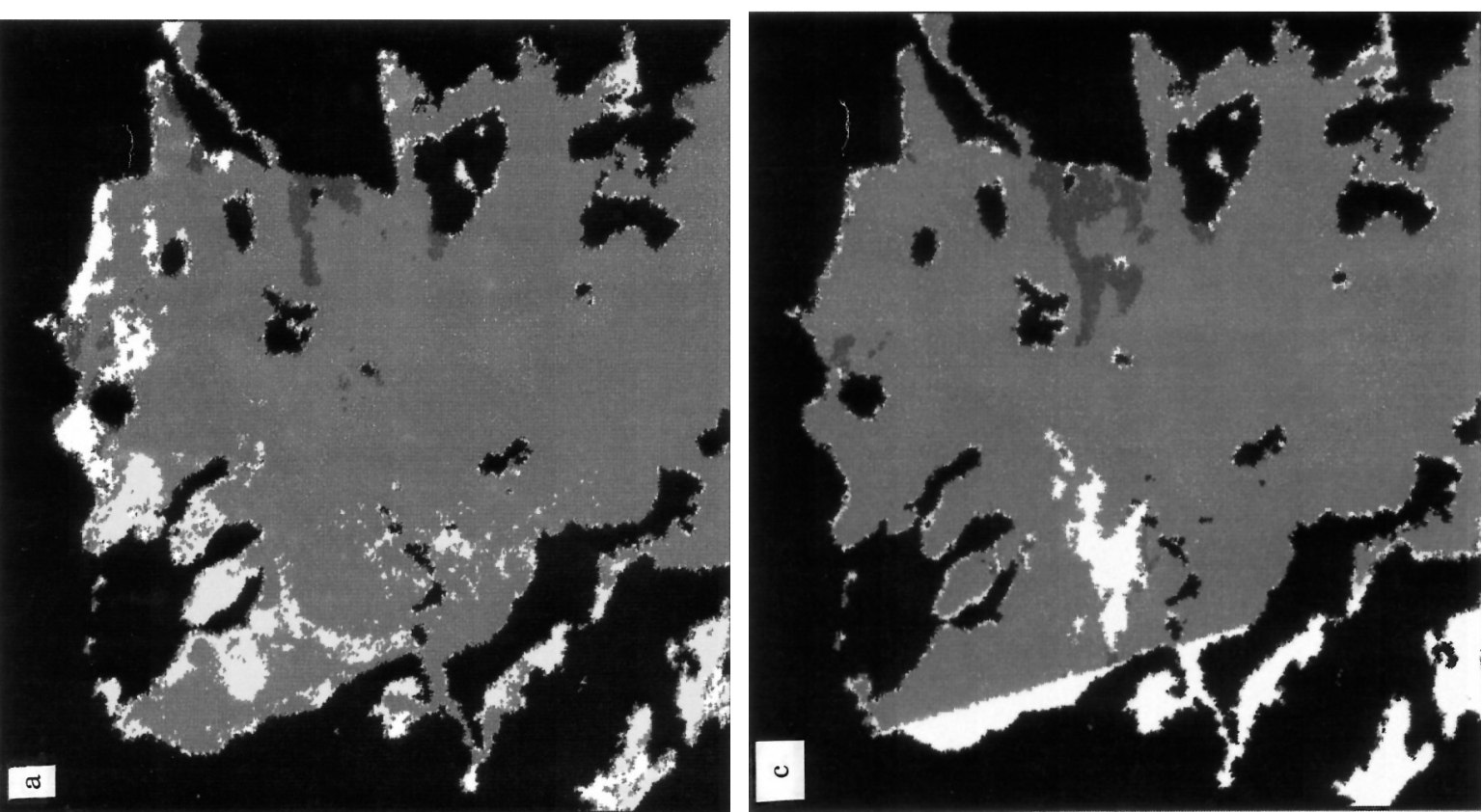

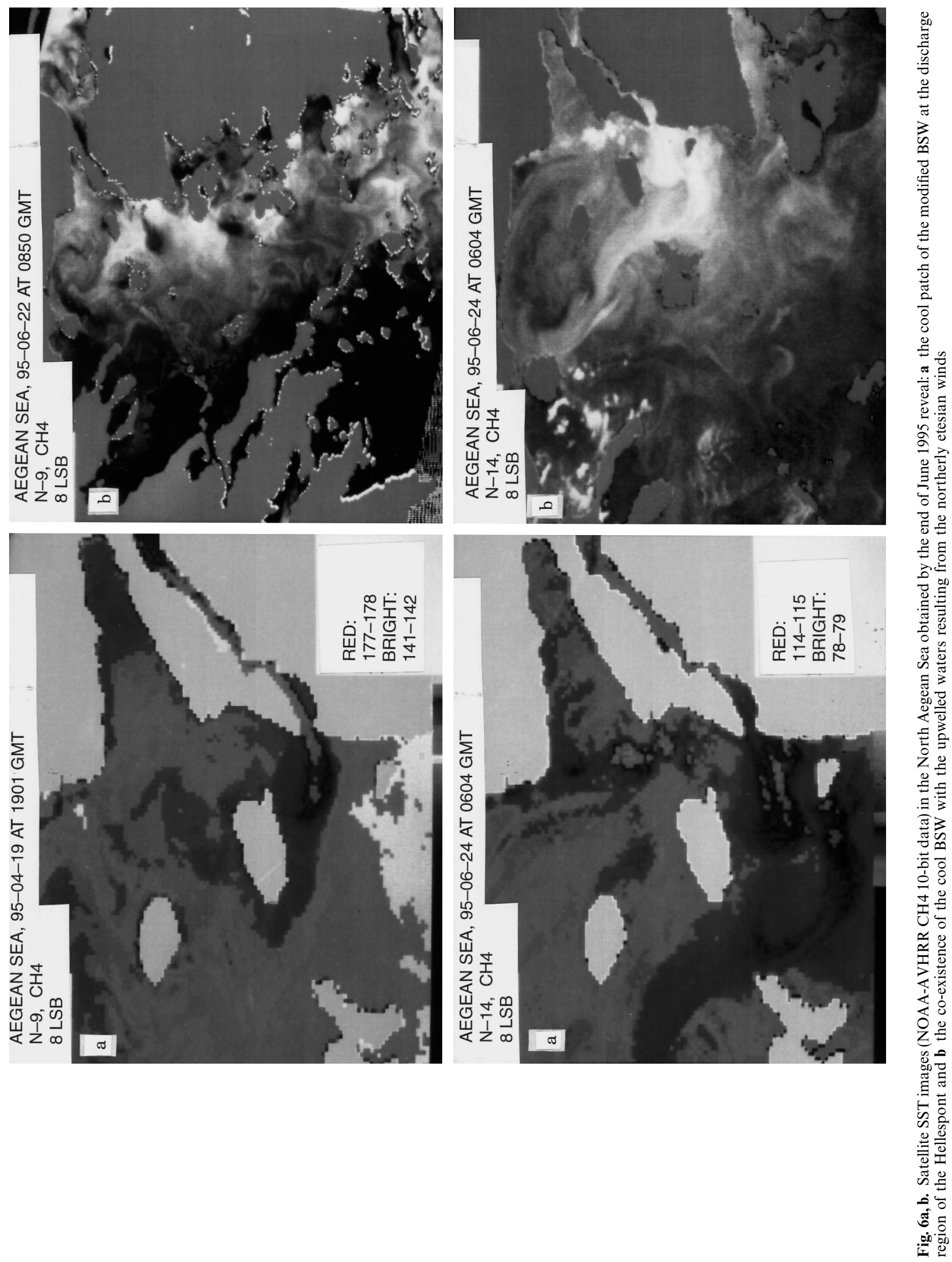
resolution about $0.5^{\circ} \mathrm{C}$, were used in order to obtain the necessary information on the sea surface water movements (Fig. 5):
a. NOAA-11 1993-06-27 at 1409 GMT
b. NOAA-11 1993-06-29 at 1345 GMT
c. NOAA-11 1993-07-02 at 1309 GMT

\section{d. NOAA-11 1993-07-04 at 1424 GMT}

The satellite data was available from a remote sensing centre in Heraklio, Crete. It is worth mentioning that the thermal images were obtained at about the same time, midday between 1300 and 1400 GMT, and thus the influence of any temporal variations in the sea surface temperature due to any differences between the detection time is minimal.

The NOAA-AVHRR thermal images (Fig. 5) reveal that the cool water (about $19{ }^{\circ} \mathrm{C}$ ) near the strait entrance can be attributed to the modified BSW. Moreover, a temperature difference was indicated between the western and eastern parts of the North Aegean Sea. This temperature difference of about $2-3{ }^{\circ} \mathrm{C}$ results from the upwelling phenomena mentioned earlier. The present thermal images were obtained at the beginning of the warm period, when northerly winds initiated upwelling phenomena. Therefore, the modified BSW co-existed with the upwelled waters, especially by the end of the study period (4 July 1993). The spatial variation of the cool water near the strait entrance was associated with the well-known southward advection of the BSW origin during summer periods (Zodiatis, 1994). Therefore, the MCC method was easier to apply in the limit area of discharge region with relatively greater horizontal temperature differences. The cool patch of modified BSW and its co-existence with the upwelled waters are common phenomena near the discharge region of the Hellespont. This is also found from NOAA-AVHRR images, for June 1995 (Fig. 6) obtained from the remote sensing centre at the University of Lund.

\subsection{Current vectors and flow patterns}

The derived velocity vectors plotted on the NOAAAVHRR thermal infrared images (Fig. 7) show the dominance of southward advection for the cool water in the discharge region and surface current speed about $10-15 \mathrm{~cm} \mathrm{~s}^{-1}$. For the first pair of thermal images, the velocity vectors indicated southward movement of the cool modified BSW (Fig. 7a). The second pair of NOAAAVHRR scenes with the derived velocity vectors shows that the current south of Limnos island is directed to the

Fig. 7a-c. Current vectors in the discharge region of Hellespont derived from the MCC method and NOAA-11 AVHRR, 1993; a between 27 June, 1300 GMT and 29 June, 1345 GMT; b between 29 June, 1345 GMT and 02 July, 1309 GMT; c between 02 July, 1309 GMT and 04 July, 1424 GMT
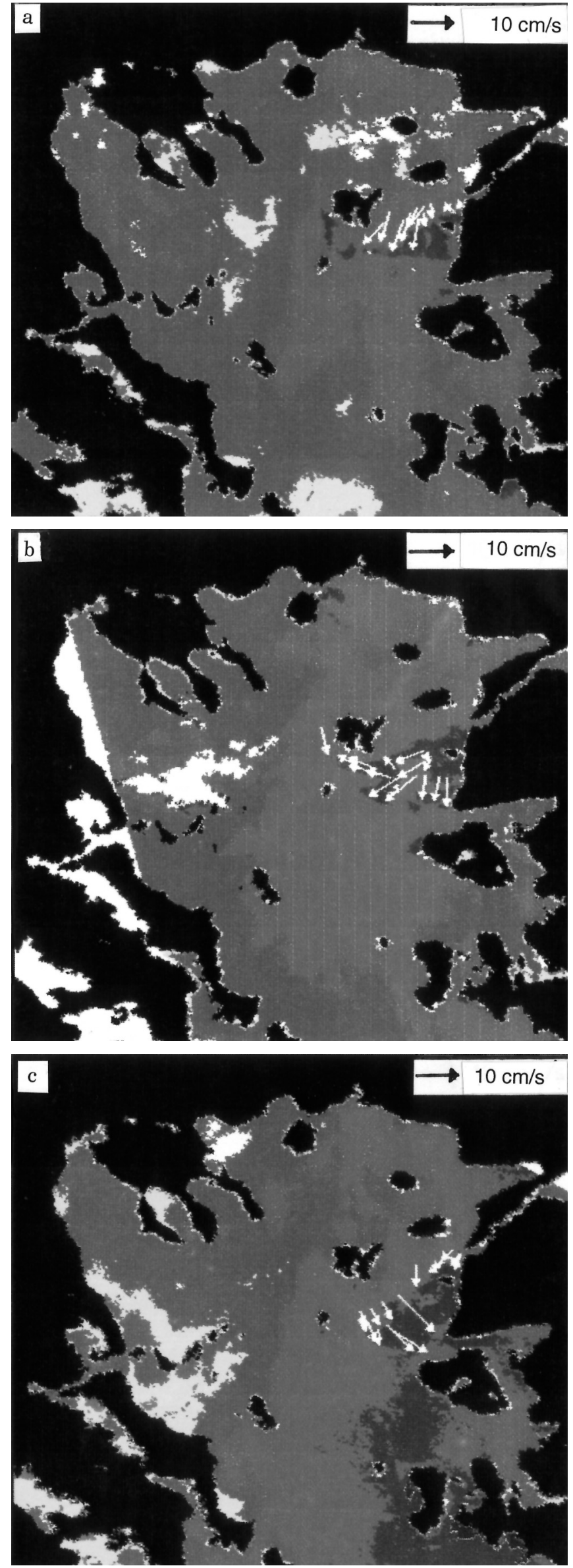

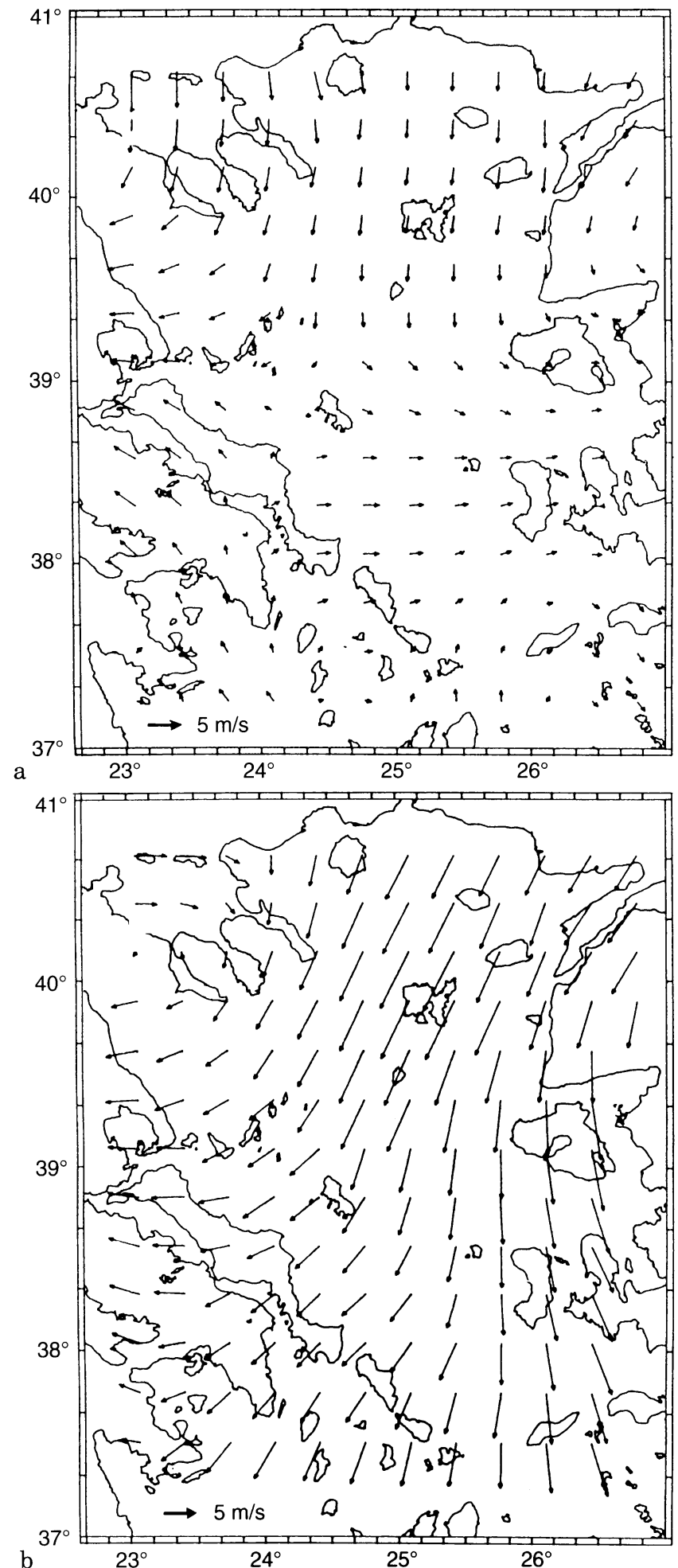

Fig. 8a, b. Wind speed fields $\left(\mathrm{m} \mathrm{s}^{-1}\right)$ over the North Aegean Sea; a for 28 June 1993; b for 02 July 1993

SW. Along the western coastline of this island, as well as near the eastern geographical boundaries of the discharge region of the Hellespont, a southward flow was found to prevail (Fig. 7b). In the last pair of satellite scenes, at the southeastern part of the discharge region, the derived currents were directed to the southeast, while near the strait entrance they were directed to the southwest (Fig. 7c).

The winds in the North Aegean Sea showed marked spatial and temporal variations during the study period (Fig. 8). In the period of 26-27 June 1993, the prevailing winds were northerly at $6-8 \mathrm{~m} \mathrm{~s}^{-1}$, then lighter $\left(2-3 \mathrm{~m} \mathrm{~s}^{-1}\right)$ from SE to NW (28-30 June 1993). Finally, during 1-4 July the wind fields were almost similar to those observed between 26-27 June 1993. The wind field variations during the period examined were the results of pressure gradient over the Hellespont, causing northerly winds between 26 and 27 June 1993. During 29 June 1993, a cold front moved over the Balkan area. Then in the next two days (30 June and 1 July 1993) the front was almost stationary with week pressure gradients. After July 1st the pressure gradient strengthened again, slowly initially and then faster when strong northerly winds $\left(6-8 \mathrm{~m} \mathrm{~s}^{-1}\right)$ reappeared.

The character of the vertically integrated flow at the surface layer $40 \mathrm{~m}$ deep in the case of one layer 2D flow model experiment (Fig. 9), induced by the winds in the North Aegean during the time period 27 June-4 July 1993, has a dynamical pattern which does not differ significantly from the scenario of the wind-driven circulation of the North Aegean simulated previously (Krestenitis et al., 1987). The wind forcing over the area sets up an anticyclonic gyre in the central part of the North Aegean during the first period (Fig. 9a), while later a current was generated with cyclonic and anticyclonic eddies (Fig. 9b). The simulated anticyclonic eddy in the NW Aegean is a semi-permanent dynamic feature of the general flow pattern of the area (Valioulis and Krestenitis, 1994; Zodiatis, 1994).

In the case of the application of a two-layer 2D flow model experiment, the flow pattern of the upper surface layer indicates a southward direction of the current in the prestrait region (attributed to the BSW current) and a mesoscale anticylonic flow region in the NW Aegean (Fig. 10), similar to that mentioned above. A different picture appears in the central and the SE part of the area, where the simulated flow pattern shows the prevalence of a southward flow through the NE passage of the Kiklades Plateau, instead of a weak inflow through the eastern part of the passage. The magnitude of the simulated depthaveraged velocity currents, at the surface layer $(0-40 \mathrm{~m})$, is generally less than $4 \mathrm{~cm} \mathrm{~s}^{-1}$, with higher values $\left(5-6 \mathrm{~cm} \mathrm{~s}^{-1}\right)$ near the prestrait region.

In agreement with the geostrophic circulation (Fig. 2b) (Lacombe et al., 1958; Ovchinnikov et al., 1976; Zodiatis, 1994), the simulated BSW current is directed from the prestrait area towards the SW passage of the North Aegean, while a weak northward flow moved through the NE passage of the Kiklades Plateau for the case of one layer 2D flow model experiment).

The flow pattern estimated by the model (Fig. 9a) was compared to the satellite derived current vectors in Fig. $7 \mathrm{a}$, while the two other satellite derived current fields (Fig. $7 \mathrm{~b}, \mathrm{c})$ were compared with the model results presented in Fig. 9b. The comparison shows agreement between the satellite statistically-derived current vectors and the 


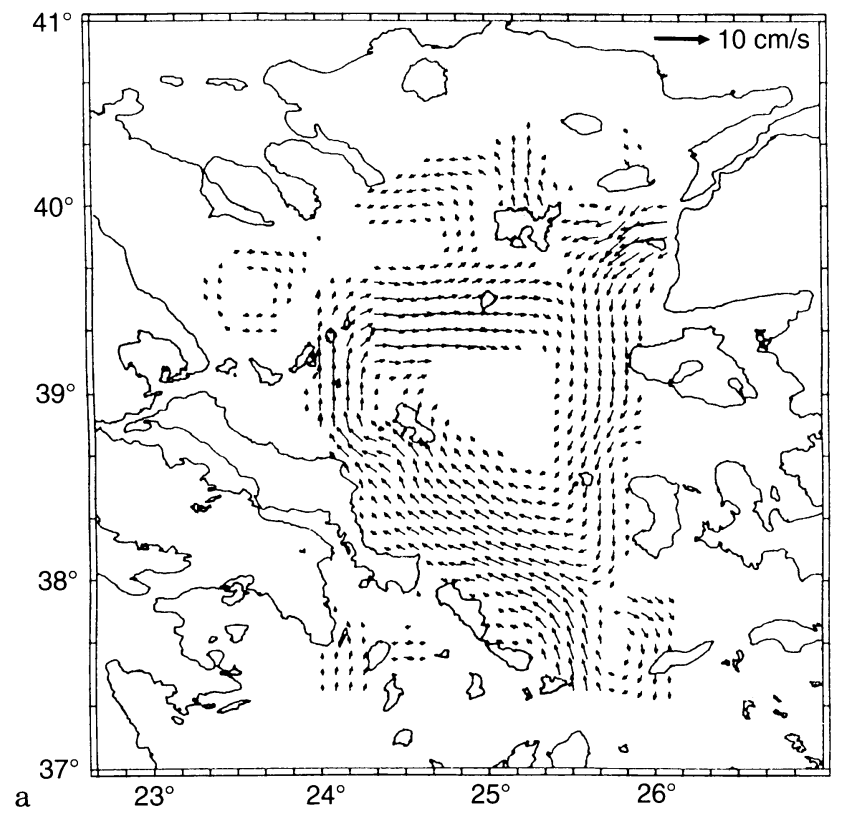

a

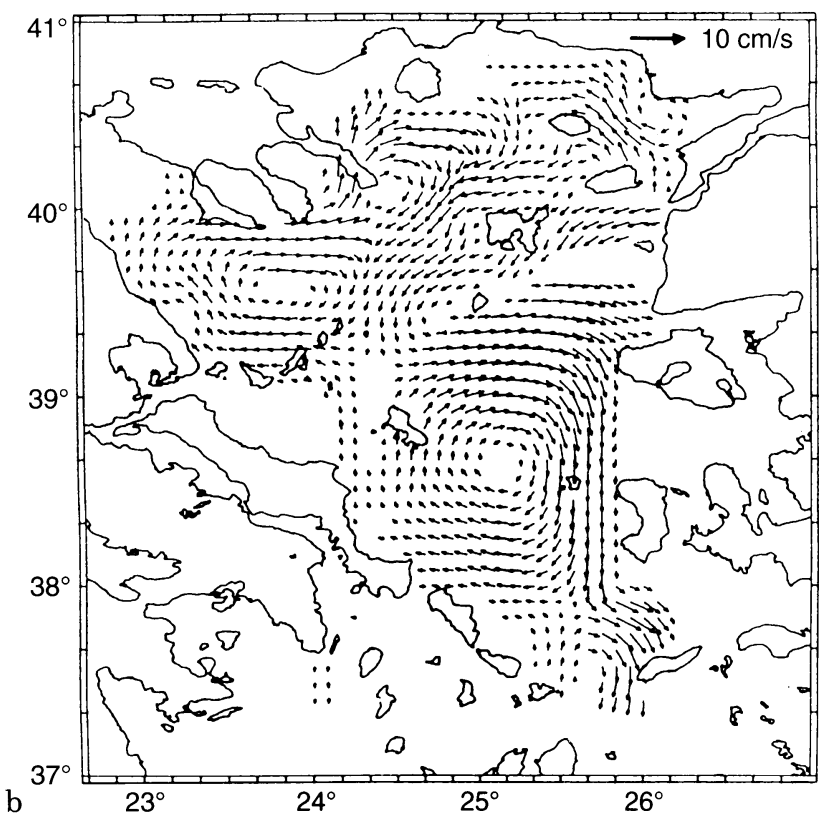

Fig. 9a, b. Simulated barotropic flow of the upper layer $(40 \mathrm{~m})$ of the North Aegean Sea, in the case of the one-layer 2D flow model experiment and the Hellespont Strait open with an average $\left(8-12 \mathrm{~cm} \mathrm{~s}^{-1}\right)$ inflow; a for 28 June 1993; b for 02 July 1993

simulated flow pattern concerning directions and magnitudes (especially in the case of one layer 2D flow model experiment) despite the simplicity of the model and the approximations were made.

\section{Conclusion}

Estimation of current vectors in the North Aegean Sea was achieved by using the MCC method on sequential satellite thermal images. The derived surface flow pattern
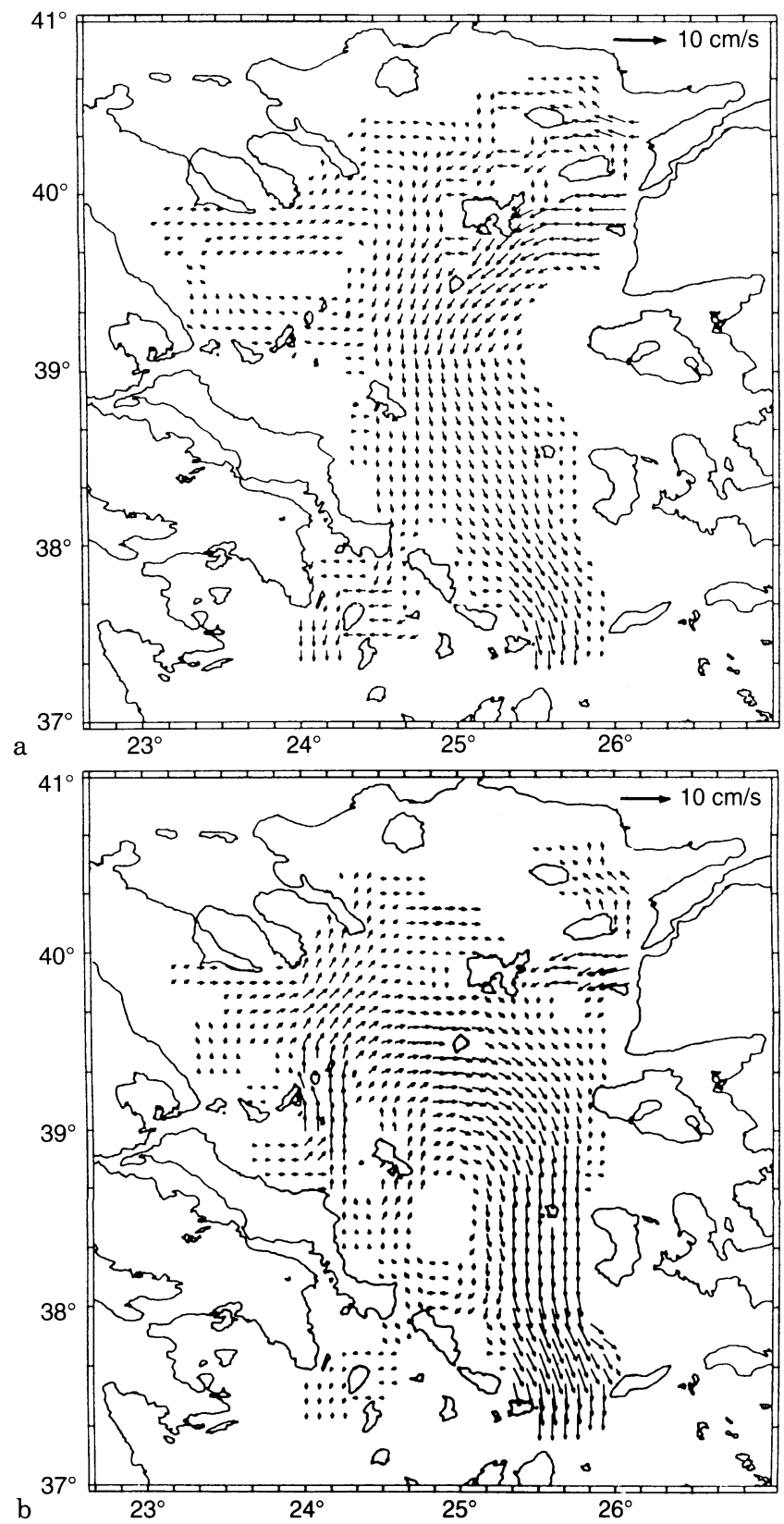

Fig. 10a, b. Simulated barotropic flow in the upper layer $(40 \mathrm{~m})$ of the North Aegean Sea, for a two-layer 2D flow model experiment; a for 30 June 1993; b for 03 July 1993 in the discharge region of the Hellespont was found to compare satisfactorily with the results of a 2D flow model, despite the model's approximations. The simulated barotropic response of the flow pattern with the Hellespont Strait open provides new information on the synpotic variability of the upper layer circulation in the North Aegean Sea. The current vectors obtained from both methods follow the scenario of the local wind-driven circulation in the case of significant inflow through the strait, take into account the approximations made and the diurnal variability of the wind fields. The satellite statistically 
derived flow patterns and the simulated ones in the discharge region indicate that the surface currents during the examined period are influenced by the inflow through the Hellespont Strait.

The encouraging results of this initial application of the MCC method will justify further and more comprehensive studies of the North Aegean Sea circulation using numerical models and satellite data simultaneously and imperatively also in situ information on velocities.

Acknowledgements. The Editor-in-Chief thanks H. Svendsen and I. Taupier-Lesage for their help in evaluating this paper.

\section{References}

Emery, W. J., A. C. Thomas, M. J. Collins, W. R. Crawford, and D. C. Mackas, An objective method for computing advective surface velocities from sequential infrared satellite images, $J$. Geophys. Res., 91, 12865-12878, 1986.

Fedorov, K. N., and A. J. Ginsburg, The near surface layer of the ocean, Ch. 5.3.1 VSP, Utrecht, The Netherlands, 1992.

Garcia, C. A. E., Comparisons between currents derived from AVHRR imaging and a tidal model in the eastern English Channel, Dep. do Fisica, Fundacao Universidade do Rio Grande, Rio Grande Brasil, 1992.

Gertman, I. E., and Y. I. Popov, Analysis and genesis of the Aegean Sea water masses in a dense grid of stations-winter 1988, VINITI, B89, 1201, Sebastopol, 1989.

Ivanov, V. A., T. P. Kovalenko, and Ye. G. Nikolayenko, Structure and characteristics of fronts in the Mediterranean Sea in summer of 1986, Oceanology, 29, 434-437, 1989.

Jonsson, L., Flow studies of the northern part of the Strait of Oresund by means of remote sensing, in Proc. 4th AVHRR Data User's Meeting, Rothenburg, Germany, Sept., 229-234, 1989.

Jonsson, L., Determination of flow velocities using NOAA-AVHRR thermal data, in EUMETSAT, 6th AVHRR Data User's Meeting, Belgirate, Italy, June 19-July 2, 1993.

Kallos, G., P. Kassomenos, and R. A. Pielke, Synoptic and mesoscale weather conditions during air pollution episodes in Athens, Greece, Boundary-Layer Meteorol., 62, 163-184, 1993.

Kielmann, J., Grundlagen und Anwendung eines Numerischen Modells der Geschichteten Ostsee, Teil II, Berichte aus dem Institut fur Meereskunde an der Christian-Albrechts-Universitat, Kiel, 87a, 1982.
Krestenitis, Y. N., N. Hasiltzoglou, and C. Koutitas, Regularities of the mathematical modelling of the Aegean Sea circulation, Proc. 2nd Panhellenic Symp. Ocean. Fish., Athens, 214-231, 1987.

Lacombe, H., P. Tchernia, and G. Benoist, Contribution a l'etude hydrologique de la mer Egee en periode d'ete, Bull. Inf., COEC, 8 , 454-468, 1958,

Latif, M. A., E. Ozsoy, T. Oguz, and H. I. Sur, Volume flux measurements in the Bosporous using an acoustic Doppler current profiler, Rapp. Comm. Int. Mer Medit., 33, 221, 1992.

Le Vourch, J., C. Millot, N. Castagne, P. Le Borgne, and J. P. Orly, Atlas of thermal fronts of the Mediterranean Sea derived from satellite imagery, Mem. Inst. Oceanogr., Monaco, 16, VI-152pp, 1992.

Lee, T. N., W. J. Ho, V. Kourafalou, and J. D. Wang, Circulation on the continental shelf of the southeastern United States. Part I: subtidal response to wind and Gulf Stream forcing during winter, J. Phys. Oceanogr., 14, 1001-1012, 1984.

Metaxas, D. A., Air sea interaction in the Greek seas and resultant Etesian characteristics, University of Ioannina, Tech. Rep., 5, 1-32, 1973

Moik, J. G., Digital processing of remotely sensed images, NASA Scientific and Technical Information Branch, SP-431, Washington, 1980.

Ovchinnikov, I. M., A. E. Plakhin, L. V. Moskalenko, K. V. Neglyad, A. S. Osadchiy, A. F. Fedoseyev, V. G. Krivosheya, and K. V. Voytova, Hydrology of the Mediterranean Sea, Gidrometeoizdat, Leningrad, 375pp, 1976 (in Russian)

Ramming, H. G., and Z. Kowalik, Numerical modelling of marine hydrodynamics, Elsevier Oceanography 26, Amsterdam, 368pp, 1980.

Sekine, Y., A numerical experiment on the path dynamics of the Kuroshio with reference to the formation of large meander path south of Japan, Deep Sea Res., 37(3), 359-380, 1990.

Valioulis, I. A., and Y. N. Krestenitis, Modelling the water mass circulation in the Aegean Sea, Part I: wind stresses, thermal and haline fluxes, Ann. Geophysicae 12, 794-807, 1994.

Zodiatis, G., Circulation of the Cretan Sea water masses (eastern Mediterranean Sea), Oceanol. Acta, 16, 107-114, 1993.

Zodiatis, G., and E. Balopoulos, Structure and characteristics of fronts in the North Aegean Sea, Boll. Oceanol. Teor. Appl., XI, 2, 113-124, 1993.

Zodiatis, G., S. Alexandri, and E. Balopoulos, Modelling the synoptic scale variability of the North Aegean Sea dynamics, EGA General Assembly, Grenoble, Ann. Geophysicae, Suppl. II, 12, 247, 1994.

Zodiatis, G., Advection of the Black Sea water in the North Aegean Sea, The Global Atmos. Ocean Syst., 2, 41-60, 1994. 